University of Nebraska - Lincoln

DigitalCommons@University of Nebraska - Lincoln

Robert G. Fuller Publications and Presentations Research Papers in Physics and Astronomy

February 1966

\title{
Diffusion of the Chlorine Ion in Potassium Chloride
}

Robert Fuller

University of Nebraska - Lincoln, rfuller@neb.rr.com

Follow this and additional works at: https://digitalcommons.unl.edu/physicsfuller

Part of the Physics Commons

Fuller, Robert, "Diffusion of the Chlorine Ion in Potassium Chloride " (1966). Robert G. Fuller Publications and Presentations. 1.

https://digitalcommons.unl.edu/physicsfuller/1

This Article is brought to you for free and open access by the Research Papers in Physics and Astronomy at DigitalCommons@University of Nebraska - Lincoln. It has been accepted for inclusion in Robert G. Fuller Publications and Presentations by an authorized administrator of DigitalCommons@University of Nebraska - Lincoln. 


\title{
Diffusion of the Chlorine Ion in Potassium Chloride*
}

\author{
Robert G. Fuller $\dagger$ \\ Department of Physics, University of Illinois, Urbana, Illinois
}

(Received 8 September 1965)

\begin{abstract}
The diffusion coefficient of the chlorine ion was measured in pure single crystals of potassium chloride and in crystals containing mole fractions of strontium chloride between $2.1 \times 10^{-5}$ and $4.69 \times 10^{-4}$. The results were consistent with the assumption that both anion vacancies and vacancy pairs contribute to the diffusion of the chlorine ion. The diffusion coefficient of the chlorine ion in pure potassium chloride was well represented by the equation $D=61 \exp (-2.12 \pm 0.05 \mathrm{eV} / k T) \mathrm{cm}^{2} / \mathrm{sec}$ from 560 to $760^{\circ} \mathrm{C}$. The anion-vacancy contribution to the chlorine-ion diffusion coefficient in pure potassium chloride was $D_{a}=36.5 \exp [-(2.10 \mathrm{eV}) / k T] \mathrm{cm}^{2} / \mathrm{sec}$ and the mole fraction of Schottky defects was $n_{0}=43.9$ $\times \exp [-(2.31 \mathrm{eV}) / 2 k T]$. The jump activation energy of the anion vacancy was $0.95 \mathrm{eV}$. The vacancy-pair contribution to the diffusion coefficient of the chlorine ion was $D_{p}=8.56 \times 10^{3} \exp [-(2.65 \mathrm{eV}) / k T] \mathrm{cm}^{2} / \mathrm{sec}$. These results are in good agreement with theory. Below $560^{\circ} \mathrm{C}$, experimental diffusion coefficients in pure potassium chloride were too large to be interpreted in terms of anion-vacancy and vacancy-pair diffusion. Similar, anomalous behavior was found below $645^{\circ} \mathrm{C}$ in crystals containing $469 \mathrm{ppm}$ of strontium.
\end{abstract}

\section{INTRODUCTION}

$\mathrm{V}$ ACANCY pairs have long been a puzzle in the study of point defects in the alkali halides. As early as $1940^{1}$ it was recognized that the concentration of vacancy pairs might be comparable to that of Schottky defects, and several theoretical investigations $^{2,3}$ of the properties of pairs have been published. Experimental evidence concerning vacancy pairs has been difficult to obtain, however. Recent high-temperature, dielectric-loss measurements ${ }^{4-6}$ have been interpreted in terms of vacancy pairs, but the reported concentration of pairs is anomalously large. Aniondiffusion measurements have offered the most positive evidence concerning vacancy pairs. Since it is possible to reduce the concentration of anion vacancies and their contribution to the anion diffusion by adding a divalent cation to the alkali halides, it is possible to separate the contributions of anion vacancies and vacancy pairs to the anion-diffusion coefficient. The concentration of vacancy pairs is independent of the concentration of an impurity divalent ion. The effect of a substantial vacancy-pair contribution to the anion-diffusion coefficient is to make the diffusion coefficient much less sensitive to the presence of the divalent ion than if diffusion occurred only by an anion-vacancy mechanism.

* This research is based on a thesis submitted in partial fulfillment of the requirements for the degree of Doctor of Philosophy, and was partially supported by the U. S. Office of Naval Research under Contract No. Nonr 1834(19) and a DuPont Grant-in-Aid of Fundamental Research.

† Present address: U. S. Naval Research Laboratory, Washington, D. C.

1 N. F. Mott and R. W. Gurney, Electronic Processes in Ionic Crystals (Clarendon Press, Oxford, England, 1940), p. 41.

2 K. Tharmalingam and A. B. Lidiard, Phil. Mag. 6, 1159 (1961).

${ }^{3}$ F. G. Fumi and M. P. Tosi, Discussions Faraday Soc. 23, 92 (1957).

${ }^{4}$ N. A. Economou, Phys. Rev. 135, A1020 (1964).

5 N. A. Economou and P. V. Sastry, Phys. Status Solidi 6, 135 (1964).

${ }^{6}$ P. V. Sastry and T. M. Srinivasan, Phys. Rev. 132, 2445 (1963).
Barr, Hoodless, Morrison, and Rudham ${ }^{7}$ reported that the addition of cadmium to sodium chloride had only a small affect on the chlorine-ion diffusion coefficient. Similar results were reported by Morrison and Rudham $^{8}$ for potassium chloride containing cadmium, but their measurements were made at temperatures under $543^{\circ} \mathrm{C}$ where evidence exists that dislocations play a role in the diffusion mechanism. Definite evidence for vacancy pairs was secured by Laurance, ${ }^{9}$ who examined the effect of calcium in sodium chloride on the chlorine-ion diffusion coefficient and obtained data in good agreement with the theory of pairs. Barr, Morrison, and Schroeder ${ }^{10}$ have reported results similar to those of Laurance.

The work reported in this paper consisted of the measurement of the chlorine-ion diffusion coefficient in potassium chloride as a function of temperature and strontium concentration in order to determine the anion-vacancy and vacancy-pair contributions and compare them with theory.

\section{THEORY}

The equilibrium concentrations of cation and anion vacancies in pure potassium chloride are given by the equation ${ }^{11}$

$$
n_{0}=\exp \left(s_{s} / 2 k-h_{s} / 2 k T\right),
$$

where $n_{0}$ is the mole fraction of anion vacancies which is equal to the mole fraction of cation vacancies. The entropy and enthalpy of formation of a cation and an anion vacancy, a Schottky defect, are $s_{s}$ and $h_{s}$, respectively. In mixed crystals of potassium chloridestrontium chloride, the equilibrium concentration of

${ }^{7}$ L. W. Barr, I. M. Hoodless, J. A. Morrison, and R. Rudham, Trans. Faraday Soc. 56, 697 (1960).

8 J. A. Morrison and R. Rudham, J. Phys. Chem. Solids 6, 402 (1958).

${ }^{9}$ N. Laurance, Phys. Rev. 120, 57 (1960).

${ }^{10} \mathrm{~L}$. W. Barr, J. A. Morrison, and P. A. Schroeder, J. Appl. Phys. 36, 624 (1965)

${ }^{11}$ A. B. Lidiard, in Handbuch der Physik, edited by S. Flügge (Springer-Verlag, Berlin, 1957), Vol. XX, Part 2, pp. 246-349. 
anion vacancies $n_{a}$ is less than $n_{0}$. If it is assumed that the divalent strontium ions are randomly distributed over the cation lattice sites, the necessity that the crystal be electrically neutral yields a mole fraction of anion vacancies,

$$
n_{a}=\frac{1}{2}\left[\left(c^{2}+4 n_{0}^{2}\right)^{1 / 2}-c\right],
$$

where $c$ is the mole fraction of strontium.

The attractive interaction between cation and anion vacancies, which is chiefly electrostatic, forms electrically neutral defects, vacancy pairs, which are cation and anion vacancies on adjacent lattice sites. Their equilibrium mole fraction, which is not a function of the strontium concentration, is given by

$$
n_{p}=6 \exp \left(s_{p} / k-h_{p} / k T\right),
$$

where $s_{p}$ and $h_{p}$ are the entropy and enthalpy of formation of a vacancy pair.

Complexes (electrically neutral defects which consist of a divalent strontium ion and a cation vacancy on adjacent lattice sites) exist, but their effect was suffciently small under the conditions of the present experiments to permit their omission from the analysis of the data.

Self-diffusion of the chlorine ion may occur by the jump of a chlorine ion into a neighboring anion vacancy. The frequency of these jumps is given by

$$
f=f_{0} \exp \left(-E_{a} / k T\right)
$$

where $f_{0}$ is a constant and $E_{a}$ is the activation energy for exchange of chlorine-ion and anion-vacancy positions. The contribution of the anion vacancies to the self-diffusion coefficient of the chlorine ion is proportional to the product $n_{a} f$ and may be written as

$$
D_{a}=\left(n_{a} / n_{0}\right) D_{a 0} \exp (-W / k T),
$$

where $W=E_{a}+\frac{1}{2} h_{s}$.

In like manner, the translation of the vacancy pair may contribute to the self-diffusion coefficient of the chlorine ion. Theoretical calculations ${ }^{2}$ indicate that the activation energy for the jump of a potassium ion into the cation vacancy of a pair $E_{p}$ is sufficiently larger than that of the jump of the chlorine ion into the anion vacancy to make it the rate determining factor for translation. The contribution of vacancy pairs to the self-diffusion coefficient of the chlorine ion may be written as

$$
D_{p}=D_{p 0} \exp (-Q / k T),
$$

where $Q=E_{p}+h_{p}$.

If only anion vacancies and vacancy pairs contribute to the self-diffusion coefficient of the chlorine ion, it may be written as the sum of Eqs. (5) and (6),

$$
D_{-}=\left(n_{a} / n_{0}\right) D_{a 0} \exp (-W / k T)+D_{p 0} \exp (-Q / k T) \text {. }
$$

Equations (1), (2), and (7) were used for the analysis of the experimental data.

\section{EXPERIMENTAL PROCEDURE}

The "pure" $\mathrm{KCl}$ single crystals were supplied by the Harshaw Chemical Company. Potassium chloride crystals containing strontium were grown in our laboratory by the Kyropolous technique from Harshaw $\mathrm{KCl}$ and Baker's reagent-grade $\mathrm{SrCl}_{2} \cdot 6 \mathrm{H}_{2} \mathrm{O}$. Crystals were grown in a nitrogen atmosphere from melts containing 100,1000 , and $5000 \mathrm{ppm}$ mole fraction of strontium chloride. One crystal was grown in air from a 50-ppm mole-fraction melt. All of the doped crystals were single crystals and were annealed at $700^{\circ} \mathrm{C}$ for times ranging from $15 \mathrm{~min}$ to $12 \mathrm{~h}$ and cooled at $\frac{1}{3}{ }^{\circ} \mathrm{C}$ per minute. Samples in the form of $7-\mathrm{mm}$ cubes were cleaved from the doped and the Harshaw crystals. One face of each sample was shaved with a microtome and was coated by evaporation with a thin layer of $\mathrm{KCl}^{36}$. The evaporated layers ranged from 2 to $20 \mu$ in thickness. The samples were placed in pairs in a platinum container which was suspended in a Vycor tube in an atmosphere of dry nitrogen. These samples were heated within $3 \mathrm{~min}$ to the diffusion temperature and held at this temperature for a time sufficient to give a rootmean-square penetration depth of $45 \mu$. The times required varied from $3 \mathrm{~h}$ to 46 days. The samples were quickly cooled to room temperature and sliced with an American Optical Company type-860 microtome. The samples were aligned for slicing by the use of a binocular microscope. A slice thickness of $6 \mu$ was generally used in slicing the samples. Before each slice the surface of the $\mathrm{KCl}$ sample was painted with a fast-drying glue to which the powdered salt, removed from the sample by the microtome knife, adhered. Usually 29 slices were removed in this manner. The sliced materials were placed in liquid-scintillation counting vials. A suspension, liquid-scintillation counting technique was used to count the radioactivity of the chlorine-36. The scintillation solution was made of $5 \mathrm{~g}$ of PPO 2, 5-diphenyloxazole (scintillation grade) and $0.3 \mathrm{~g}$ of dimethyl POPOP-1, 4-bis-2-(4-Methyl-5-phenyloxazolyl)-benzene (scintillation grade) per liter of toluene. To this solution was added Cab-O-Sil M-5, a pure silica thixotropic gelling agent, to form a transparent rigid suspension solution. The counting was done with a Tri-Carb automatic liquid scintillation spectrometer, model 314X. The random errors from the statistical fluctuations in the counting rate were kept low by using slices for which the total counts were greater than 1200 and were greater than twice the background count. The diffusion coefficient was calculated by making a least-squares fit of the data to a Gaussian penetration curve. ${ }^{12}$ The diffusion coefficients were corrected for the effects of the finite slice thickness, the evaporation layer thickness, and the slicing misalignment distance. The temperature of the samples during the diffusion run was measured by a platinum-

${ }^{12} \mathrm{~W}$. Jost, Diffusion in Solids, Liquids, and Gases (Academic Press Inc., New York, 1960), p. 16. 
TABLE I. Strontium content of $\mathrm{KCl}$ crystals.

\begin{tabular}{cc}
\hline \hline $\begin{array}{c}\text { ppm mole fraction } \\
\text { in the melt }\end{array}$ & $\begin{array}{c}\text { ppm mole fraction } \\
\text { in the crystals }\end{array}$ \\
\hline Harshaw & $0.85 \pm 0.4$ \\
50 & $21.0 \pm 0.4$ \\
100 & $43.9 \pm 0.4$ \\
1000 & $237 \pm 7$ \\
5000 & $469 \pm 4$ \\
\hline
\end{tabular}

(platinum-rhodium) thermocouple placed in thermal contact with the platinum containers.

The concentrations of strontium in the samples were determined by atomic absorption using a Perkin-Elmer model-303 atomic absorption spectrophotometer. The results of the analysis are shown in Table I. The total effective impurity concentration of the Harshaw samples was estimated to be $0.5 \mathrm{ppm}$ mole fraction from the Harshaw conductivity data of Srinivasan ${ }^{13}$ and the conductivity data of Kelting and Witt ${ }^{14}$ and Gründig ${ }^{15}$ for pure and for doped potassium chloride.

\section{RESULTS}

The diffusion coefficient of the chlorine ion in "pure" Harshaw potassium chloride crystals is shown as a

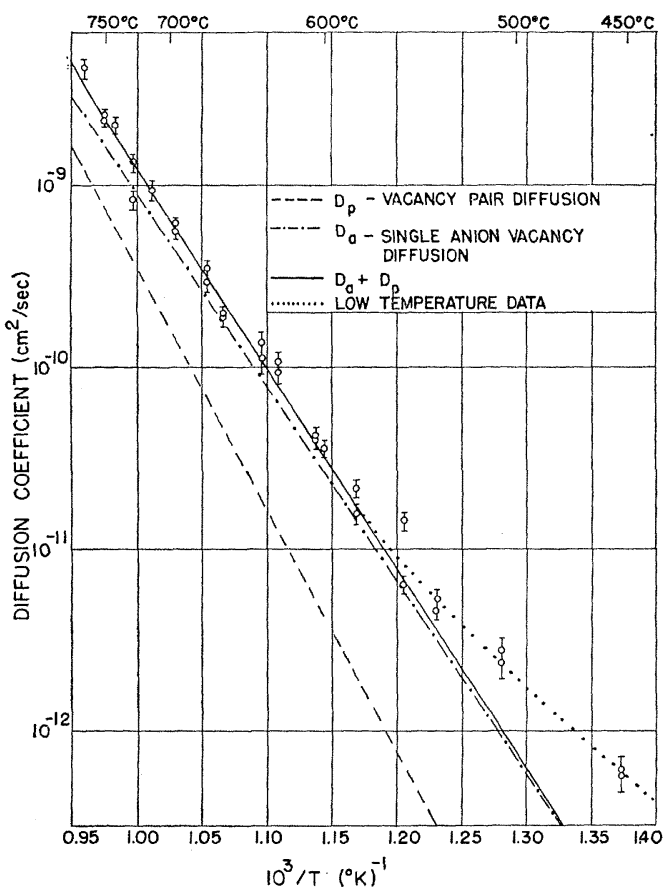

FIG. 1. Diffusion coefficient of $\mathrm{Cl}^{36}$ in "pure" $\mathrm{KCl}$, as a function of temperature. -.........-, calculated vacancy pair contribution; - - - calculated anion-vacancy contribution; bution; sum of vacancy-pair and anion-vacancy contributions; ......, low-temperature anomalous behavior.

${ }^{13}$ T. M. Srinivasan, Technical Note No. 3, AF49(638)-529, University of Illinois, 1962 (unpublished).

${ }^{14}$ H. Ketting and H. Witt, Z. Physik 126, 697 (1949).

${ }^{15}$ H. Gründig, Z. Physik 158, 577 (1960). function of temperature in Fig. 1. The data are well represented by the equation

$$
D=D_{0} \exp (-A / k T),
$$

from 560 to $760^{\circ} \mathrm{C}$ with $A=2.12 \pm 0.05 \mathrm{eV}$ and $D_{0}=61$ $\mathrm{cm}^{2} / \mathrm{sec}$. The uncertainty in the value of $A$ produces an uncertainty of $100 \%$ in the value of $D_{0}$. These data are in fair agreement with those of Laurent and Benard ${ }^{16}$ who found $D_{0}=10 \pm 5 \mathrm{~cm}^{2} / \mathrm{sec}$ and $A=1.99 \pm 0.03 \mathrm{eV}$ between the temperatures of $520^{\circ} \mathrm{C}$ and $755^{\circ} \mathrm{C}$. Barr, Hoodless, Morrison, and Rudham ${ }^{7}$ found $A=2.6 \mathrm{eV}$ for temperatures above $540^{\circ} \mathrm{C}$ but, as reference to Fig. 2 shows, their small estimated divalent-cation impurity content of about $8 \mathrm{ppm}$ may explain their large value for $A$.

The $\log D$-versus- $T^{-1}$ curve for Harshaw potassium chloride has positive curvature below $560^{\circ} \mathrm{C}$. Similar anomalous behavior has been observed in potassium chloride and in sodium chloride and attributed to diffusion along dislocations. ${ }^{7}$

The diffusion coefficient of the chlorine ion in crystals containing strontium is shown in Figs. 2 and 3. The diffusion coefficients of the crystals containing 21 and $43.9 \mathrm{ppm}$ strontium were the same as those of the Harshaw crystals for temperatures above $720^{\circ} \mathrm{C}$. The high-temperature diffusion mechanisms are intrinsic

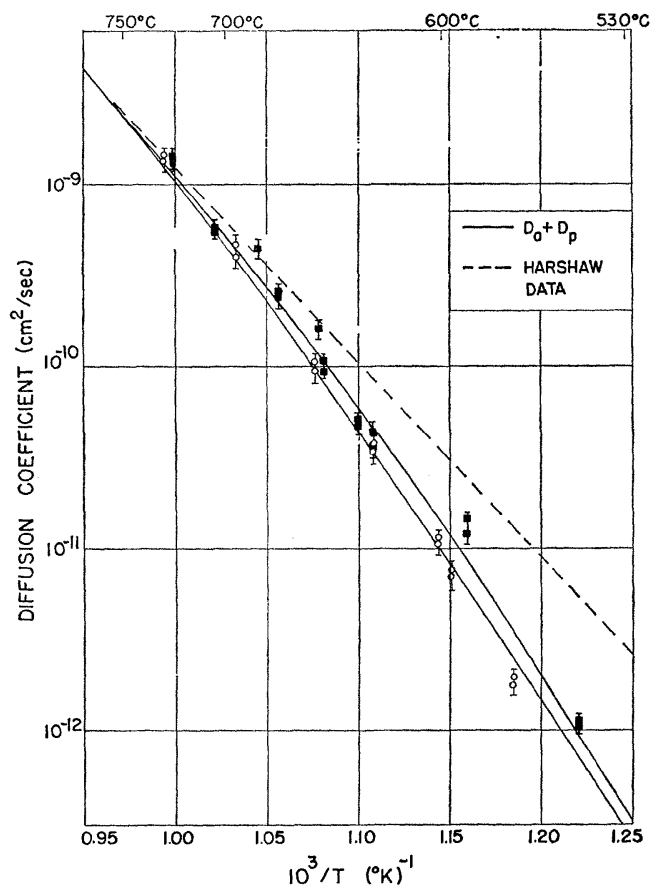

FIG. 2. Diffusion coefficient of $\mathrm{Cl}^{36}$ in $\mathrm{KCl}$ containing $\mathrm{Sr}$, as a function of temperature. - - - - - Eq. (8) representing the Harshaw crystal data. $\square, 21.0 \mathrm{ppm}$ mole fraction strontium; $\mathrm{O}$, $43.9 \mathrm{ppm}$ mole fraction strontium; - , calculated diffusion coefficients [see Eqs. (1), (2), and (7)].

${ }^{16} \mathrm{~J}$. F. Laurent and J. Benard, J. Phys. Chem. Solids 3, 7 (1957). 
and not influenced by the strontium impurity. The diffusion coefficients of the crystals containing 237 and $469 \mathrm{ppm}$ of strontium are almost equal for temperatures above $650^{\circ} \mathrm{C}$. An intrinsic diffusion mechanism which is independent of the strontium impurity, such as the vacancy-pair mechanism, is dominant at high temperatures in these heavily doped crystals. The $\log D$-versus$T^{-1}$ curve of the crystal containing $469 \mathrm{ppm}$ of strontium has positive curvature below $645^{\circ} \mathrm{C}$. This behavior cannot be explained by a combination of anion-vacancy and vacancy-pair contributions to the diffusion coefficient.

The data of Figs. 1, 2, and 3 cannot be interpreted solely in terms of anion-vacancy diffusion. The combination of anion-vacancy and vacancy-pair contributions to the diffusion coefficient as expressed by Eqs. (1), (2), and (7) does yield excellent agreement with the data, as is shown by the calculated solid curves of Figs. 1, 2, and 3. These curves were obtained by fitting Eq. (7), and Eqs. (1) and (2), to the data with an IBM 7094 computer. The data from the lowtemperature regions of positive curvature were omitted from the analysis. The omitted data were the Harshaw crystal data of Fig. 1 for $10^{3} / T>1.20$, the 237-ppm data of Fig. 3 for $10^{3} / T>1.12$, and the 469 -ppm data of Fig. 3 for $10^{3} / T>1.09$. A total of 75 data points was used to determine the best values of the six parameters $s_{s}, h_{s}, D_{a 0}, W, D_{p 0}$, and $Q$. The anion-vacancy contri-

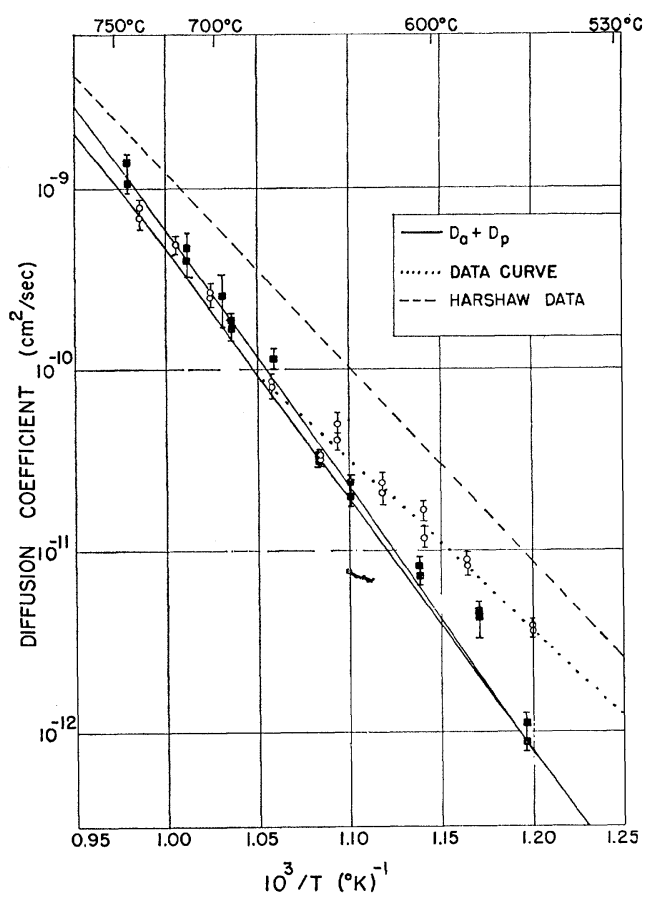

FIG. 3. Diffusion coefficient of $\mathrm{Cl}^{36}$ in $\mathrm{KCl}$ containing $\mathrm{Sr}$, as a function of temperature. - - - - - Eq. (8) representing the Harshaw crystal data. $\mathbf{n}, 237 \mathrm{ppm}$ mole fraction strontium; 0 , $469 \mathrm{ppm}$ mole fraction strontium; - - calculated diffusion coefficients [see Eqs. (1), (2), and (7)]; $\cdots \cdots$, anomalous behavior of 469-ppm Sr samples.
TABLE II. Experimental results and theoretical values.

\begin{tabular}{clc}
\hline \multicolumn{1}{c}{ Quantity } & $\begin{array}{c}\text { Theoretical } \\
(\mathrm{eV})\end{array}$ & $\begin{array}{c}\text { Experiment } \\
(\mathrm{eV})\end{array}$ \\
\hline $\begin{array}{c}\text { Activation energy of vacancy- } \\
\text { pair diffusion coefficient, } Q\end{array}$ & $2.58^{\mathrm{a}}$ & $2.65 \pm 0.1$ \\
$\begin{array}{c}\text { Activation energy of single anion- } \\
\text { vacancy diffusion coefficient, } W\end{array}$ & $2.3^{\mathrm{b}}$ & $2.10 \pm 0.1$ \\
$\begin{array}{c}\text { Energy of formation of a } \\
\quad \text { Schottky defect, } h_{s}\end{array}$ & $2.2^{\mathrm{b}}$ & $2.31 \pm 0.1$ \\
$\begin{array}{c}\text { Activation energy for jump of } \\
\text { single anion vacancy, } E_{a}\end{array}$ & $1.18^{\mathrm{c}}$ & $0.95 \pm 0.1$ \\
\hline \hline
\end{tabular}

a See Ref. 2. Born-Mayer-Verwey potential.

b See Ref. 3. Born-Mayer potential.

' See Ref. 19. Born-Mayer-Verwey potential.

bution to the diffusion coefficient in pure potassium chloride was found to be

$$
D_{a}=36.5 \exp (-2.10 \mathrm{eV} / k T) \mathrm{cm}^{2} / \mathrm{sec} \text {. }
$$

The vacancy-pair contribution to the diffusion coefficient was

$$
D_{p}=8.56 \times 10^{3} \exp (-2.65 \mathrm{eV} / k T) \mathrm{cm}^{2} / \mathrm{sec},
$$

and the mole fraction of anion vacancies (or Schottky defects) in pure potassium chloride was

$$
n_{0}=43.9 \exp [-(2.31 \mathrm{eV}) / 2 k T] \text {. }
$$

The jump activation energy of the anion vacancy $E_{a}=0.95 \mathrm{eV}$ was obtained from the difference of $W$ and $\frac{1}{2} h_{s}$. The diffusion data of Laurent and Benard ${ }^{16}$ when vacancy pairs are neglected yield $E_{a}=0.84 \mathrm{eV}$ and when corrected for the vacancy pair contribution of Eq. (10) yield $E_{a}=0.75 \mathrm{eV}$. The results obtained from conductivity data are much higher; values of $1.77 \mathrm{eV}^{17}$ and $1.87 \mathrm{eV}^{18}$ have been reported. The best theoretical value is probably $1.18 \mathrm{eV} .^{19}$ Laurance $^{9}$ obtained $E_{a}=1.11 \mathrm{eV}$ for the anion vacancy in sodium chloride. Table II shows satisfactory agreement between the experimental values of $Q, W, h_{s}$, and $E_{a}$ and theoretical calculations. An estimation of the experimental errors and of the accuracy of the computer analysis ${ }^{20}$ indicates that the precision of the activation energies may not be better than $\pm 0.1 \mathrm{eV}$ and the pre-exponential factors are probably known to within a factor of 2 . The entropy of formation of Schottky defects in potassium chloride has not been calculated. The pre-exponential factor of Eq. (11) yields $s_{s}=7.54 k$, which is in agreement with the value of $7.1 \pm 2.3 k$ reported by Dreyfus and Nowick ${ }^{21}$ from conductivity measurements. The analysis of their data ignored, however, the anion contribution to the conductivity.

${ }^{17}$ A. R. Allnatt and P. W. M. Jacobs, Trans. Faraday Soc. 58, 116 (1962).

${ }_{18}^{18}$ P. W. M. Jacobs and J. N. Maycock, Jr., J. Phys. Chem. Solids 24, 1693 (1963).

${ }_{10}$ R. Guccione, M. P. Tosi, and M. Asdente, J. Phys. Chem. Solids 10, 162 (1959).

${ }^{20}$ R. G. Fuller, Ph.D. thesis, University of Illinois, 1965 (unpublished).

${ }^{21}$ R. W. Dreyfus and A. S. Nowick, J. Appl. Phys. Suppl. 33, 473 (1962). 


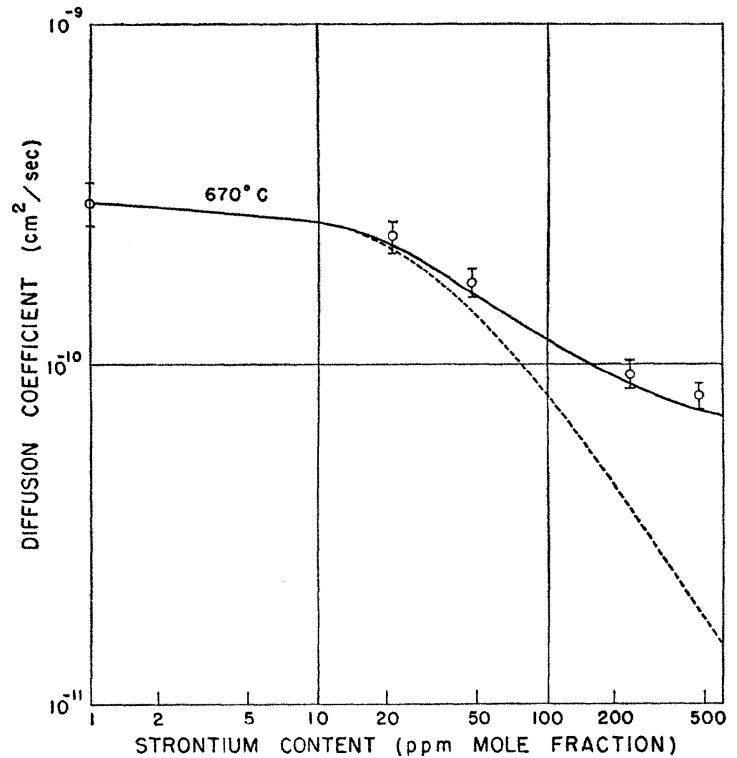

FIG. 4. Diffusion coefficient of $\mathrm{Cl}^{36}$ in $\mathrm{KCl}$ as a function of strontium content at $670^{\circ} \mathrm{C}$. - calculated diffusion coefficients [see Eqs. (1), (2), and (7)]; - - - - - calculated assuming only anion-vacancy mechanism for diffusion. $0,670^{\circ} \mathrm{C}$ values of solid curves in Figs. 1, 2, and 3.

The diffusion coefficient of the chlorine ion in potassium chloride as a function of strontium content at $670^{\circ} \mathrm{C}$ is shown in Fig. 4 . The solid curve represents the diffusion coefficient as a function of strontium content as determined by the computer analysis. The open circles are the $670^{\circ} \mathrm{C}$ values of the solid curves in Figs. 1, 2, and 3. The dashed curve represents the best fit to the data that can be obtained if it is assumed that anion vacancies are solely responsible for the diffusion. This assumption is clearly inadequate.

\section{DISCUSSION}

The vacancy-pair contribution to the diffusion coefficient of the chlorine ion in potassium chloride varies from $50 \%$ of the anion-vacancy contribution near the melting point $776^{\circ} \mathrm{C}$ to $8 \%$ at $525^{\circ} \mathrm{C}$. The effect of vacancy pairs is apparent, for pure potassium chloride, in the data of Fig. 1 in a slight positive curvature of the $\log D$-versus- $1 / T$ curve at the highest temperatures. The vacancy-pair contribution $D_{p}$ is also not negligible by comparison with the diffusion coefficient of the potassium ion. Potassium-ion diffusion data are meager, unfortunately, but Aschner's2 ${ }^{22}$ data can be approximated by the equation

$$
D=3.82 \exp [-(1.88 \mathrm{eV}) / k T] \mathrm{cm}^{2} / \mathrm{sec} .
$$

Subtraction of the vacancy-pair contribution, as given by Eq. (10), gives the cation-vacancy contribution to

\footnotetext{
${ }^{22} \mathrm{~J}$. F. Aschner, Ph.D. thesis, University of Illinois, 1954 (unpublished).
}

the diffusion coefficient of the potassium ion as

$$
D_{c}=0.54 \exp [-(1.74 \mathrm{eV}) / k T] \mathrm{cm}^{2} / \mathrm{sec} \text {. }
$$

An activation energy of $E_{c}=0.59 \mathrm{eV}$ for the jump of a cation vacancy is obtained from Eq. (13) if the enthalpy of formation of Schottky defects is taken as $2.31 \mathrm{eV}$ from Eq. (11).

The cation- and anion-vacancy contributions to the diffusion coefficients of the potassium and chlorine ions can be used to calculate the transport numbers $t_{c}$ and $t_{a}$. The transport numbers are defined as

$$
\begin{gathered}
t_{c}=\sigma_{c} /\left(\sigma_{c}+\sigma_{a}\right), \\
t_{c}+t_{a}=1,
\end{gathered}
$$

where $\sigma_{c}$ and $\sigma_{a}$ are the cation and anion contributions to the total electrical conductivity. $D_{c}$ and $D_{a}$ may be substituted for $\sigma_{c}$ and $\sigma_{a}$ in Eq. (14) by the NernstEinstein relation. ${ }^{11}$ Table III compares the cation transport number calculated in this manner from Eqs. (9) and (13) with the measured transport numbers of Kerkhoff..$^{23}$ Kerkhoff's low temperature cation transport numbers may be somewhat high because of the effect of accidental divalent-cation impurities. Table III indicates that it is not possible to assume, as has commonly been done, that the anion contribution to the hightemperature conductivity is negligible.

It is possible to sketch qualitatively the behavior of the conductivity of pure potassium chloride as a function of temperature from Eqs. (9) and (13) and the Nernst-Einstein relation. Between 400 and $760^{\circ} \mathrm{C}$ the plot of $\log (\sigma T)$ versus $1 / T$ is a curve of slight positive curvature. Above $700^{\circ} \mathrm{C}$ the slope of the $\log (\sigma T)$ versus $-1 / T$ curve is determined by an activation energy of approximately $2.0 \mathrm{eV}$. The apparent activation energy decreases to about $1.9 \mathrm{eV}$ near $525^{\circ} \mathrm{C}$ and is $1.75 \mathrm{eV}$ for temperatures below $400^{\circ} \mathrm{C}$.

Allnatt and Jacobs ${ }^{17}$ were the first to observe this curvature of the $\log (\sigma T)$-versus- $1 / T$ conductivity plot for pure potassium chloride. They properly attributed the curvature to the presence of anion conductivity. The "knee" in their plot, however, was near $575^{\circ} \mathrm{C}$, and they interpreted the region from 575 to $480^{\circ} \mathrm{C}$ as one of pure cation conductivity with an activation energy of $1.87 \mathrm{eV}$. Since the anion transport number may be as large as 0.3 in this temperature region, an

TABLE III. Cation transport numbers for $\mathrm{KCl}$.

\begin{tabular}{ccc}
\hline \hline $\begin{array}{c}\text { Temperature } \\
\left({ }^{\circ} \mathrm{C}\right)\end{array}$ & $\begin{array}{c}\text { Aschner- } \\
\text { Fuller }\end{array}$ & $\begin{array}{c}\text { Measured by } \\
\text { Kerkhoff }\end{array}$ \\
\hline 525 & $0.75 \pm 0.1$ & 0.88 \\
570 & $0.70 \pm 0.1$ & $0.81,0.82$ \\
600 & $0.67 \pm 0.1$ & $0.69,0.71,0.72$ \\
650 & $0.60 \pm 0.1$ & $\ldots$ \\
700 & $0.55 \pm 0.1$ & $\ldots$ \\
750 & $0.49 \pm 0.1$ & $\ldots$ \\
\hline
\end{tabular}

${ }^{23}$ F. Kerkhoff, Z. Physik 130, 449 (1957). 
activation energy for the jump of a cation vacancy of $0.75 \mathrm{eV}$, which is too large, was obtained. Similarly, the activation energy for the jump of the anion vacancy, $1.77 \mathrm{eV}$, which was obtained from this treatment of the data, is too large.

The conductivity of very pure potassium chloride has been measured by Gründig. ${ }^{24}$ His plot of $\log \sigma$ versus $1 / T$ shows the characteristics to be expected from the present diffusion data and that of Aschner. The plot is a straight line at the highest temperatures with a slope corresponding to an activation energy of $2.01 \mathrm{eV}$. Near $500^{\circ} \mathrm{C}$ there is a slight "knee" in the plot and the activation energy for the low-temperature, straight-line portion of the plot is $1.79 \mathrm{eV}$. The inescapable conclusion is that the data represent pure cation conductivity at low temperatures, a mixture of cation and anion conductivity at high temperatures, and that Gründig's suggestion of an electronic contribution to the low-temperature conductivity is unnecessary.

The mole fraction of thermal vacancies in pure potassium chloride as determined by this experiment is compared in Table IV with the results obtained from conductivity data. In the analysis of their data, Allnatt and Jacobs ${ }^{17}$ and Jacobs and Maycock ${ }^{18}$ took into consideration the effect of an anion contribution to the conductivity, whereas Dreyfus and Nowick ${ }^{20}$ made no allowance for anion charge transport.

Even though the combination of anion vacancy and vacancy pair contributions to the diffusion yields excellent agreement with the data, there are two regions in which the diffusion coefficients deviate from their calculated values. These regions are the low-temperature Harshaw data and 469-ppm strontium data. Barr, Hoodless, Morrison, and Rudham ${ }^{7}$ observed a "knee"

${ }^{24}$ H. Gründig, Z. Physik 182, 477 (1965).
TABLE IV. Fractional concentration of Schottky defects in pure $\mathrm{KCl}$.

\begin{tabular}{|c|c|c|}
\hline \multicolumn{3}{|c|}{$n_{0}=N_{0} \exp \left(-h_{s} / 2 k T\right)$} \\
\hline & $N_{0}$ & $(\mathrm{eV})$ \\
\hline $\begin{array}{l}\text { Dreyfus and Nowick } \\
\text { Allnatt and Jacobs } \\
\text { Jacobs and Maycock }^{\mathrm{c}} \\
\text { Present work }\end{array}$ & $\begin{array}{l}34.8_{-24}^{+77} \\
56.2^{+1} \\
48.0^{+44} \\
43.9_{-22}\end{array}$ & $\begin{array}{l}2.22 \pm 0.12 \\
2.30 \\
2.28 \\
2.31 \pm 0.1\end{array}$ \\
\hline
\end{tabular}

a See Ref. 20.

'See Ref. 18.

in the curve of the anion diffusion coefficient of $\mathrm{KCl}$ versus $T^{-1}$ similar to the one observed in the Harshaw data at $560^{\circ} \mathrm{C}$. They attributed the low-activationenergy diffusion below the "knee" to dislocations because the activation energy changed with annealing of the crystals. The diffusion coefficient versus $T^{-1}$ curve for the 469-ppm strontium crystals also possessed a "knee," but at a temperature of about $650^{\circ} \mathrm{C}$. The explanation for the anomalous behavior of the 469-ppm data is not known. The large amount of impurity may facilitate the formation of dislocations which, in turn, may offer routes of rapid anion diffusion. The investigation of the effects of strain and annealing on heavily doped crystals should be most interesting.

\section{ACKNOWLEDGMENTS}

I thank Professor R. J. Maurer for his assistance and advice, Professor R. F. Nystrom of the University of Illinois Radiocarbon Laboratory for his help with the radioactivity counting technique, and Dr. J. W. O'Laughlin and his group at Iowa State University for their performance of the chemical analysis of the crystals. 